\title{
OPTIMIZING MANUFACTURER PROFIT IN DOWNSTREAM RETAIL MARKETS UNDER CONDITIONS OF UNCERTAINTY
}

\author{
Evan C. Moore \\ Auburn University at Montgomery • Montgomery, AL \\ James D. Francisco \\ Auburn University at Montgomery • Montgomery, AL
}

\section{ABSTRACT}

Abstract: This paper presents the results of three differing sales incentives, from the manufacturer, in models involving a manufacturer selling a product to Cournot-type retailers competing in the retail market. We investigate the effectiveness of these incentives under two scenarios: profit maximizing retailers and retailers with an incentive function that is a mix between sales and profits. The optimal sales incentive is discussed.

\section{INTRODUCTION AND LITERATURE REVIEW}

As the saying goes, "the only thing worse than a monopolist is two monopolists." Thus is the problem of double marginalization, first explored by Spengler (1950). The problem arises when a "downstream" monopolist is dependent on inputs from an "upstream" monopolist. The result is a sub-optimal solution: both of the monopolists suffer losses, and the resulting inefficiencies cause a "welfare loss," or loss of value to society as a whole.

The double marginalization problem, which involves monopolists in both the upstream and downstream markets, has been viewed from a variety of perspectives. Bresnahan and Reiss (1985) extended the standard double marginalization model into a "successive monopoly" model, showing largely Stackelberg behavior, which is a situation in which one firm functions as a "leader," and the other as a "follower." The authors found that the most important factor influencing the manufacturerretailer relationship was the curvature of the demand curve.

Other studies have extended Bresnahan and Reiss' approach to evaluate its impact on certain other economic phenomena, such as price discrimination (Cowans, 2012), tax incidence (Weyl and Fabinger, 2013), and "cost pass through", or the extent to which price changes in response to a change in marginal cost (Adachi and Ebina, 2014), all finding similar results.

Hegji and Moore (2006) evaluated a similar scenario under both Stackelberg conditions, described above, and Cournot conditions, which refers to a situation 
in which firms make decisions on output based on anticipated output decisions of the other firm. They found that under certain circumstances, franchise fees were an effective tool for manufacturers to maximize profits, and also control retail prices. The manufacturer's use of a franchise fee amounts to a two-part tariff; the manufacturer sells units to retailers and charges each retailer a franchise fee. The franchise fee is used by the manufacturer to capture the retailers' profits, thereby increasing the manufacturer's own profits. Hegji and Moore also found that such franchise fees could offset the potential welfare losses suffered under double marginalization.

Some firms (and similar entities) address the problems of competing manufacturer/retailer incentives (including, inter alia, double marginalization) by engaging in resale price maintenance (RPM). RPM is an agreement between a manufacturer and dealer through which the dealer agrees to a retail price floor for the sale of a manufacturer's products. A substantial literature on RPM exists, including Hamilton (1990) and others, examining RPM as a solution to double marginalization and other problems.

All of the studies cited above assume profit maximization at every stage by each firm in the analysis; Fershtman and Judd (1987), drawing upon Baumol (1958) and others, examine the possibility of alternative objective functions (such as sales maximization) in an imperfectly competitive environment. Specifically, Fershtman and Judd contemplated mixed objective functions in the context of a principal-agent problem faced by owners seeking to incentivize optimal behavior by managers. Fershtman and Judd found that in an oligopoly situation, owners may wish to provide incentives in order to shift their managers' incentives away from strict profit maximization.

We extend the approaches cited above by considering cases involving a manufacturer interacting with downstream retailers in an imperfectly competitive retail market. Specifically, we examine how such a manufacturer can use sales incentives to encourage retailers to increase sales, with the manufacturer's ultimate aim being to increase its profit. This paper presents the results of 4 different scenarios, in models involving a manufacturer selling a product to Cournot-type retailers competing in the retail market. These include no sales incentive, a constant per-unit incentive, a sales incentive as a function of a retailer's own-sales, and an incentive as a function of the total retail sales of the manufacturer's product.

We build upon the Fershtman and Judd (1987) approach by investigating 2 different types of objective functions: retailers focused solely on profits, and retailers with mixed objective functions involving a mix between sales and profits. We seek to determine what the optimal sales incentive is from the manufacturer's perspective 
under the different objective functions, under conditions of uncertainty relating to the retailers' objective function, and conditions of uncertainty with regard to retail demand. Further, in keeping with the Spengler (1950) approach, we determine which solution most ameliorates the welfare problems presented by double marginalization.

\section{MODEL AND RESULTS}

A manufacturer is dependent on sales in the downstream, imperfectly competitive, market by retailers engaged in Cournot-type competition. We attempt to model two potential forms of an objective function for the retailer: pure profit maximization, as well as a mixed objective function for profit maximization combined with revenue maximization. We present the derivation of the pure profit maximization case below. We start with the inverse retail demand function - or, the demand for a good expressed in terms of the price of the good rather than the quantity of the good - in a market with $n$ retailers:

(1) $P_{R}=A-B X=A-B \sum x_{i}, i=1, \ldots, n$

Where $P_{R}$ represents the price the retailer receives.

For a pure profit maximization approach, the retailer's objective function would be represented as follows:

(2) $\pi_{i}=[A-B X] x_{i}-P_{M} x_{i}$.

Where $P_{M}$ represents the price paid to the manufacturer by the retailers.

The profit maximizing manufacturer faces the following profit maximizing objective function:

(3) $\pi_{M}=\left(P_{M}-C_{M}\right) X$.

We first consider the situation in which the retailer operates as a pure profit maximizer according to (2), and the manufacturer offers no sales incentives. To do so we begin by determining a retailer's reaction function. The reaction function for retailer $i$ indicates the best response, i.e. profit maximizing level of retail sales for firm $i$, given the sales produced by the other retailers. The derivation of the reaction function is in section A.1. of the appendix. In this case, maximization of (2) results in the $i^{\text {th }}$ retailer's reaction function:

(4) $x_{i}=\frac{A-B \bar{X}_{i}-P_{M}}{2 B}$, where $\bar{X}_{i}=X-x_{i}$. Due to symmetry in retailer output, $\bar{X}_{i}=(n-1) x_{i}$ 
Solving (4) results in the $i^{\text {th }}$ retailer's output of

(5) $x_{i}=\frac{A-P_{M}}{B(n+1)}$

and use of (5) in the demand function results in the equilibrium retail price of

(6) $P_{R}=\frac{A+n P_{M}}{n+1}$.

Use of (5) in equation (3) and maximization of the manufacturer's profit with respect to $P_{M}$ results in:

(7) $P_{M}=\frac{\left(A+C_{M}\right)}{2}$.

Using (7) in the various equations results in equilibrium results of

(8) $P_{R}=\frac{2 A+A n+C_{M} n}{2(n+1)}$,

(9) $x_{i}=\frac{\left(A-C_{M}\right)}{2 B(n+1)}$,

(10) $\pi_{R}=\frac{\left(A-C_{M}\right)^{2}}{4 B(n+1)^{2}}$,

(11) $\pi_{M}=\frac{n\left(A-C_{M}\right)^{2}}{4 B(n+1)}$.

When retailers are operating with mixed objective functions, a retailer's objective function would be represented as follows:

(12) $O B J_{i}=\lambda_{i} \pi_{i}+\left(1-\lambda_{i}\right) P_{R} x_{i}$.

Lambda $(\lambda)$ represents the weight that a retailer places on profit maximization and $(1-\lambda)$ the weight on sales maximization; it follows that $0 \leq \lambda \leq 1$. The derivations for the results of the retailers with mixed objective functions is in section A.2. of the appendix.

Table 1 presents the results from retailers operating with pure profit maximizing and mixed objective functions. 
Table 1

\section{Equilibrium Results With No Sales Incentives}

\begin{tabular}{|l|c|c|}
\hline Variable & Pure Profit Max & Mixed Objective Function \\
\hline Retailer's Price & $P_{R}=\frac{2 A+A n+C_{M} n}{2(n+1)}$ & $P_{R}=\frac{2 A+n^{2}\left(A+C_{M}\right)}{2\left(n^{2}+1\right)}$ \\
\hline Retailer's Sale & $x_{i}=\frac{\left(A-C_{M}\right)}{2 B(n+1)}$ & $x_{i}=\frac{n\left(A-C_{M}\right)}{2 B\left(n^{2}+1\right)}$ \\
\hline Manufacturer's Price & $P_{M}=\frac{\left(A+C_{M}\right)}{2}$ & $P_{M}=\frac{\left(A+C_{M}\right)}{2}$ \\
\hline Retailer's Profit & $\pi_{R}=\frac{\left(A-C_{M}\right)^{2}}{4 B(n+1)^{2}}$ & $\pi_{R}=\frac{n\left(A-C_{M}\right)^{2}}{4 B\left(n^{2}+1\right)^{2}}$ \\
\hline Manufacturer's Profit & $\pi_{M}=\frac{n\left(A-C_{M}\right)^{2}}{4 B(n+1)}$ & $\pi_{M}=\frac{n^{2}\left(A-C_{M}\right)^{2}}{4 B\left(n^{2}+1\right)}$ \\
& & $\lambda_{i}=\frac{n C_{M}(n+1)+A\left(2-n+n^{2}\right)}{\left(A+C_{M}\right)\left(n^{2}+1\right)}$ \\
\hline
\end{tabular}

As expected, a retailer's sales are greater under the mixed objective function. Similarly, the manufacturer's profit is greater when retailers compete using mixed objective functions due to the increased sales.

We provide equations (13) - (15) below to allow for useful comparisons with the above results and the various sales incentive results to follow. These equations are the results if the manufacturer is able to retail directly, i.e. there are no downstream retailers, with no additional costs.
(13) $P_{R}=P_{M}=\frac{\left(A+C_{M}\right)}{2}$,
(14) $X=\frac{\left(A-C_{M}\right)}{2 B}$, 
(15) $\pi_{M}=\frac{\left(A-C_{M}\right)^{2}}{4 B}$.

A comparison of equation (15) with the manufacturer's profits in Table 1 reveals that the manufacturer would enjoy increased profits from retailing directly with no additional costs. The manufacturer would provide a higher level of units for sale while maintaining its price $\left(P_{M}\right)$. As increased sales lead to greater manufacturer profits, up to the level indicated in equation (14), the manufacturer has an interest in increasing retailers' sales through sales incentives.

We investigate 3 potential options of various per-unit sales incentives from the manufacturer to the retailer. These are a:

1. Constant per unit incentive $(d)$; this incentive is a fixed amount $(d)$ provided to a retailer for each unit $\left(x_{i}\right)$ sold. For example, the manufacturer may offer a sales incentive of $\$ 1$ per unit sold.

The profit maximizing retailer's profit function in this case is

$$
\pi_{i}=[A-B X] x_{i}-P_{M} x_{i}+d x_{i} .
$$

The mixed objective retailer's function in this case is

$$
O B J_{i}=\lambda_{i} \pi_{i}+\left(1-\lambda_{i}\right) P_{R} x_{i}+d x_{i} .
$$

2. Per unit incentive that is a function of an individual retailer's own sales $\left(d x_{i}\right)$; this incentive increases as a retailer increases its own sales. For example, if $d$ $=\$ 1$, then a retailer selling 2 units will receive a $\$ 2$ sales incentive for each unit sold, whereas a retailer selling 3 units will receive a $\$ 3$ sales incentive for each unit sold.

The profit maximizing retailer's profit function in this case is

$$
\pi_{i}=[A-B X] x_{i}-P_{M} x_{i}+\left(d x_{i}\right) x_{i} .
$$

The mixed objective retailer's function in this case is

$$
O B J_{i}=\left[A-B X-\lambda_{i} P_{M}\right] x_{i}+\left(d x_{i}\right) x_{i}
$$

3. Per unit incentive that is a function of all retailer sales $\left(d\left(\sum_{i=1} x_{i}\right)\right)$; this incentive increases as the total sales, i.e. the sales of all retailers in the market, increases. For example, suppose $d=\$ 1$ and there are 2 retailers in the market selling 2 and 3 units respectively. The each retailer will receive a $\$ 5$ sales incentive for each unit sold. 
The profit maximizing retailer's profit function in this case is $\pi_{i}=[A-B X] x_{i}-P_{M} x_{i}+\left(d\left(\sum_{i=1}^{n} x_{i}\right)\right) x_{i}$.

The mixed objective retailer's function in this case is $O B J_{i}=\lambda_{i} \pi_{i}+\left(1-\lambda_{i}\right) P_{R} x_{i}+d\left(\sum_{i=1}^{n} x_{i}\right) x_{i}$.

A general model of a manufacturer using per-unit sales incentives involves the manufacturer attempting to maximize its profits, $\pi_{M}\left(P_{M}, d\right)$,subject to the following constraints:

$$
\begin{aligned}
& \pi_{i} \geq 0 \\
& x_{i} \geq 0 \\
& P_{R} \geq 0 \\
& P_{M} \geq 0 \\
& d \geq 0
\end{aligned}
$$

These contraints indicate that each retailer must have nonnegative profits $\left(\pi_{i}\right)$ and sales $\left(x_{i}\right)$ in equilibrium. Note that retailer profits of zero are normal economic profits; this indicates that the retailer has covered all costs of production, including both explicit and implicit costs. Additionally, the prices charged by the retailer $\left(P_{R}\right)$ and manufacturer $\left(P_{M}\right)$ must be nonnegative. The component $(d)$ of any sales incentive offered must be nonnegative as well.

Finally, if the manufacturer is to offer sales incentives it must be the case that its profit from offering the incentives is at least as large as it would be from not offering any sales incentives.

The derivations for these models, with results presented in Tables 2 through 4 below, are presented in the appendix; those for the profit maximizing retailers are in section A.3. and for the mixed objective retailers in section A.4.

Table 2 presents the results from the manufacturer offering a constant per-unit incentive (d) to retailers operating with pure profit maximizing or mixed objective functions. 
Table 2

\section{Equilibrium Results With Constant Per Unit Sales Incentives}

\begin{tabular}{|l|c|c|}
\hline Variable & Pure Profit Max & Mixed Objective Function \\
\hline Retailer's Price & $P_{R}=\frac{2 A+A n+C_{M} n}{2(n+1)}$ & $P_{R}=\frac{2 A+n^{2}\left(A+C_{M}\right)}{2\left(n^{2}+1\right)}$ \\
\hline Retailer's Sale & $x_{i}=\frac{\left(A-C_{M}\right)}{2 B(n+1)}$ & $x_{i}=\frac{n\left(A-C_{M}\right)}{2 B\left(n^{2}+1\right)}$ \\
\hline Manufacturer's Price & $P_{M}=\frac{\left(A+C_{M}\right)}{2}+d$ & $P_{M}=\frac{\left(A+C_{M}\right)}{2}+d$ \\
\hline Retailer's Profit & $\pi_{R}=\frac{\left(A-C_{M}\right)^{2}}{4 B(n+1)^{2}}$ & $\pi_{R}=\frac{n\left(A-C_{M}\right)^{2}}{4 B\left(n^{2}+1\right)^{2}}$ \\
\hline Manufacturer's Profit & $\pi_{M}=\frac{n\left(A-C_{M}\right)^{2}}{4 B(n+1)}$ & $\pi_{M}=\frac{n^{2}\left(A-C_{M}\right)^{2}}{4 B\left(n^{2}+1\right)}$ \\
\hline Lambda & $\mathrm{NA}$ & $\lambda_{i}=\frac{n(n+1)}{\left(n^{2}+1\right)}-\frac{(A+d)(n-1)}{d+\frac{1}{2}\left(A+C_{M}\right)\left(n^{2}+1\right)}$ \\
\hline
\end{tabular}

The use of a constant per unit incentive, $d$, does not result in any change in the manufacturer's profits. This is evident by a comparison of the manufacturer's profits from Tables 1 and 2 in each of the profit maximizing and mixed objective function retailers scenarios. Similarly, the retailers in each case earn similar profits as those they would earn if no incentive was used. This is due to the manufacturer increasing its price $\left(P_{M}\right)$ by the amount of the per unit incentive, $\mathrm{d}$, in equilibrium.

Table 3 presents the results from the manufacturer offering a per unit incentive that is a function of an individual retailer's own sales, $\left(d x_{i}\right)$, to retailers operating with pure profit maximizing or mixed objective functions. 
Table 3

Equilibrium Results With Per Unit Incentives That Are A Function Of An Individual Retailer's Own Sales

\begin{tabular}{|c|c|c|}
\hline Variable & Pure Profit Max & Mixed Objective Function \\
\hline Retailer's Price & $P_{R}=A-\frac{B n\left(A-C_{M}\right)}{2(B-d+B n)}$ & $P_{R}=A-\frac{B n\left(A-C_{M}\right)(B n-2 d)}{2\left(2 d^{2}-B d(2+3 n)+B^{2}\left(n^{2}+1\right)\right)}$ \\
\hline Retailer's Sale & $x_{i}=\frac{\left(A-C_{M}\right)}{2(B-d+B n)}$ & $x_{i}=\frac{\left(A-C_{M}\right)(B n-2 d)}{2\left(2 d^{2}-B d(2+3 n)+B^{2}\left(n^{2}+1\right)\right)}$ \\
\hline Manufacturer's Price & $x_{i}=\frac{\left(A-C_{M}\right)(B n-2 d)}{2\left(2 d^{2}-B d(2+3 n)+B^{2}\left(n^{2}+1\right)\right)}$ & $P_{M}=\frac{A B\left(-2 d(n+1)+B\left(n^{2}+1\right)\right)+C_{M}\left(4 d^{2}-2 B(d+2 d n)+B^{2}\left(n^{2}+1\right)\right)}{2\left(2 d^{2}-B d(2+3 n)+B^{2}\left(n^{2}+1\right)\right)}$ \\
\hline Retailer's Profit & $\pi_{R}=\frac{\left(A-C_{M}\right)^{2}(B-d)}{4(B-d+B n)^{2}}$ & $\pi_{R}=\frac{\left(A-C_{M}\right)^{2}\left(B^{3} n-4 d^{3}+4 B d^{2}(n+1)-B^{2} d\left(2+2 n+n^{2}\right)\right)}{4\left(2 d^{2}-B d(2+3 n)+B^{2}\left(n^{2}+1\right)\right)^{2}}$ \\
\hline Manufacturer's Profit & $\pi_{M}=\frac{n\left(A-C_{M}\right)^{2}}{4(B-d+B n)}$ & $\pi_{M}=\frac{n\left(A-C_{M}\right)^{2}(B n-2 d)}{4\left(2 d^{2}-B d(2+3 n)+B^{2}\left(n^{2}+1\right)\right)}$ \\
\hline Lambda & NA & $\lambda_{i}=\frac{C_{w}\left(4 d^{2}+B^{2} n(n+1)-2 B(d+2 d n)\right)+A B\left(-2 d(n+1)+B\left(2-n+n^{2}\right)\right)}{A B\left(-2 d(n+1)+B\left(n^{2}+1\right)\right)+C_{m}\left(4 d^{2}-2 B(d+2 d n)+B^{2}\left(n^{2}+1\right)\right)}$ \\
\hline
\end{tabular}

The per unit incentive, which is a function of an individual retailer's own sales, $\left(d x_{i}\right)$ may indeed be profit maximizing but the manufacturer must be certain of the retailer's behavior. If the retailers are profit maximizing then the manufacturer will want to set $d=B$, i.e when the sales incentive piece, $d$, is set equal to the slope of the inverse demand function, B. This will result in the manufacturer's profit being equal to that of retailing directly without additional costs, equation (15). However, in the mixed objective case the manufacturer must set the sale incentive piece, $d$, less than $B$. This is evident from manufacturer's profit with retailers using mixed objective functions. A retailer's profit in this scenario binds if $d=1 / 4(2 B+B n-B \sqrt{ }(-$ $\left.4+4 n+n^{2}\right)$ ), which is a decreasing function of the number of retailers, $n$. As the retailers are already selling more than they would be if they were profit maximizing, a value of $d$ in excess of the binding value would encourage them to sell too many 
units, potentially decreasing the manufacturer's profit or leading to retailers suffering negative profits. If the manufacturer is uncertain of the retailers' behavior then this introduces uncertainty regarding the choice of $d$.

Table 4 presents the results from the manufacturer offering a per unit incentive that is a function of all retailer sales, $\left(d\left(\sum_{i=1}^{n} x_{i}\right)\right)$, to retailers operating with pure profit maximizing or mixed objective functions.

Table 4

Equilibrium Results With Per Unit Incentives That Are A Function of All Retailer's Sales

\begin{tabular}{|l|c|c|}
\hline Variable & Pure Profit Max & Mixed Objective Function \\
\hline Retailer's Price & $P_{R}=A-\frac{B n\left(A-C_{M}\right)}{2(B-d+B n)}$ & $P_{R}=A-\frac{B n^{2}\left(A-C_{M}\right)}{2\left(B-d+B n^{2}\right)}$ \\
\hline Retailer's Sale & $x_{i}=\frac{\left(A-C_{M}\right)}{2(B-d+B n)}$ & $x_{i}=\frac{n\left(A-C_{M}\right)}{2\left(B-d+B n^{2}\right)}$ \\
\hline Manufacturer's Price & $P_{M}=\frac{C_{M}(B-d)(n+1)+A(d(n-1)+B(n+1))}{2(B-d+B n)}$ & $P_{M}=\frac{C_{M}(B-d)\left(n^{2}+1\right)+A\left(d\left(n^{2}-1\right)+B\left(n^{2}+1\right)\right)}{2\left(B-d+B n^{2}\right)}$ \\
\hline Retailer's Profit & $\pi_{R}=\frac{\left(A-C_{M}\right)^{2}(B-d)}{4(B-d+B n)^{2}}$ & $\pi_{R}=\frac{n\left(A-C_{M}\right)^{2}(B-d)}{4\left(B-d+B n^{2}\right)^{2}}$ \\
\hline Manufacturer's Profit & $\pi_{M}=\frac{n\left(A-C_{M}\right)^{2}}{4(B-d+B n)}$ & $\pi_{M}=\frac{n^{2}\left(A-C_{M}\right)^{2}}{4\left(B-d+B n^{2}\right)}$ \\
\hline Lambda & $\mathrm{NA}$ & $\lambda_{i}=\frac{n C_{M}(n+1)(B-d)+A\left(B\left(2-n+n^{2}\right)+d\left(n+n^{2}-2\right)\right)}{C_{M}\left(n^{2}+1\right)(B-d)+A\left(d\left(n^{2}-1\right)+B\left(n^{2}+1\right)\right)}$ \\
\hline
\end{tabular}

The use of a per unit incentive that is a function of all retailer sales $\left(d\left(\sum_{i=1}^{n} x_{i}\right)\right)$ can lead to manufacturer profits equal to those of the manufacturer selling directly to the final consumers with no additional retailing costs. Note that the manufacturer's profits in Table 4 are equal to equation (15) when the sales incentive piece, $d$, is set 
equal to the slope of the inverse demand function, $B$. In both the profit maximizing and mixed objective cases the retailers would end up with normal economic profits. Note that it is not important, from the manufacturer's point of view, whether the retailers are profit maximizing or using mixed objective functions.

\section{Numerical Example}

Table 5 provides numerical solutions to the equations in Tables 1-4. Note that the headings from the previous tables are changed; "Pure Profit Max" is reduced to " $\pi$ " and "Mixed Objection Function" to "MOF" to allow for comparisons in one table. The values of the variables are as follows:

$$
\begin{aligned}
& A=10 \\
& B=1 \\
& C_{M}=1 \\
& n=4 \\
& d \text { varies among the tables. }
\end{aligned}
$$

This coincides with a retail inverse demand function of $P_{R}=10-X$; costs to the manufacturer of 1 per unit; and 4 retail firms in the market.

\section{Table 5}

Numerical Solutions For Equilibrium Results Listed in Tables 1 - 4.

\begin{tabular}{|l|l|l|l|l|l|l|l|l|l|l|}
\hline & \multicolumn{2}{|c|}{$\begin{array}{c}\text { Table 1 } \\
(\boldsymbol{d}=\mathbf{0})\end{array}$} & \multicolumn{2}{c|}{$\begin{array}{c}\text { Table 2 } \\
(\boldsymbol{d}=\mathbf{0 . 5})\end{array}$} & \multicolumn{3}{c|}{ (d=1) } & \multicolumn{3}{c|}{ Table 3 } \\
& & $\boldsymbol{d}=\mathbf{0 . 1 7 7 )}$ & \multicolumn{2}{c|}{$\begin{array}{c}\text { Table 4 } \\
(\boldsymbol{d}=1)\end{array}$} \\
\hline Variable & $\pi$ & MOF & $\pi$ & MOF & $\pi$ & MOF & $\pi$ & MOF & $\pi$ & MOF \\
\hline Retailer's Price & 6.4 & 5.76 & 6.4 & 5.76 & 5.5 & 2.8 & 6.27 & 5.5 & 5.5 & 5.5 \\
\hline Retailer's Sales & 0.9 & 1.06 & 0.9 & 1.06 & 1.13 & 0.8 & 0.93 & 1.13 & 1.13 & 1.13 \\
\hline $\begin{array}{l}\text { Manufacturer's } \\
\text { Price }\end{array}$ & 5.5 & 5.5 & 6 & 6 & 6.75 & 7.3 & 5.68 & 5.7 & 10 & 10 \\
\hline Retailer's Profit & 0.81 & 0.28 & 0.81 & 0.28 & 0 & -1.22 & 0.72 & 0 & 0 & 0 \\
\hline $\begin{array}{l}\text { Manufacturer's } \\
\text { Profit }\end{array}$ & 16.2 & 19.06 & 16.2 & 19.06 & 20.25 & 32.4 & 16.79 & 20.25 & 20.25 & 20.25 \\
\hline Lambda & N/A & 0.855 & N/A & 0.841 & N/A & 0.630 & N/A & 0.838 & N/A & 1 \\
\hline
\end{tabular}

A comparison of the numerical results for the Table 1 and 2 columns reveals that a constant per unit incentive is ineffective at increasing the profitability of the manufacturer. The manufacturer's profit remains 16.2 when facing profit maximizing retailers and 19.06 when facing retailers with mixed objective functions. 
The maximum profit for the manufacturer, when selling the product directly without retailing costs, in this example is 20.25 . As noted in the discussion surrounding Table 3, the choice of $d$ depends on the objectives of the retailers. If the retailers are profit maximizing then the manufacturer will set $d=B$, in this example equal to 1 , to maximize profits. However, this results in negative profits for retailers with mixed objective functions and therefore cannot be an equilibrium in this case. When facing mixed objective retailers, the manufacturer will have to restrict $d$ to 0.177 to result in maximum profits of 20.25. But with this lower value of $d$, if the manufacturer is in fact facing profit maximizing retailers then the manufacturer's profit increases only by 0.59 , from 16.2 to 16.79 . As discussed earlier, if the manufacturer is uncertain of the retailers' behavior then this introduces uncertainty regarding the choice of $d$.

Finally a comparison of the columns regarding Table 4, involving per unit incentives that are a function of all retailer sales, reveals that this sales incentive approach maximizes the manufacturer's profits and leads to the retailers providing identical levels of sales regardless of whether they compete under profit maximizing or mixed objective functions.

\section{$\overline{\text { CONCLUSION }}$}

We examined how two alternative objective functions affect downstream retailer behavior, and how such alternate specifications are impacted by various incentive structures offered by an upstream manufacturer. We find that a constant per unit incentive is ineffective in increasing sales or the manufacturer's profits, regardless of whether the retailers are engaged in profit maximization or using a mixed objective function. Our results show that a per unit incentive, which is a function of an individual retailer's own sales, (dxi) may indeed be profit maximizing but the manufacturer must be certain of the retailers' behavior. If the manufacturer is unsure of the retailers' objective functions, then setting the value of $\mathrm{d}$ incorrectly will lead to profits below those of the manufacturer retailing directly without retailing costs. We find that in both retailer scenarios the optimal solution from the manufacturer's perspective is to create a per-unit incentive that is a function of total retailer sales. By setting the sales incentive piece, $d$, equal to the slope of the inverse demand function, $\mathrm{B}$, the manufacturer is able to increase sales and earn profits equal to those of retailing directly. Additionally, the market is more efficient as this sales incentive results in greater total surplus, or value to society, due to increased consumer surplus and greater joint profits. 


\section{$\overline{\text { APPENDIX }}$}

A.1. Reaction function derivation - the equation numbers in this section of the appendix match those found in the body of the text

The profits of the ith retailer are:

(2) $\pi_{i}=[A-B X] x_{i}-P_{M} x_{i}$.

The reaction function is found by differentiating (2) with respect to $x_{i}$, which results in:

$$
\frac{\partial \pi_{i}}{\partial x_{i}}=A-B \bar{X}_{i}-2 B x_{i}-P_{M}
$$

Set this derivative equal to zero and solve for $x_{i}$. This results in the ith retailer's reaction function:

(4) $x_{i}=\frac{A-B \bar{X}_{i}-P_{M}}{2 B}$,

where $\bar{X}_{i}=X-x_{i}$. Due to symmetry in retailer output, $\bar{X}_{i}=(n-1) x_{i}$. Substituting for $\bar{X}_{i}$ in equation (4) results in the $i^{\text {th }}$ retailer's output of

(5) $x_{i}=\frac{A-P_{M}}{B(n+1)}$.

A. 2. Derivations for retailers operating with mixed objective functions

Now consider the situation in which $n$ Cournot retailers compete under incentive contracts. The objective function for the manager is $O B J_{i}=\lambda_{i} \pi_{i}+\left(1-\lambda_{i}\right) P_{R} x_{i}$. Using the demand function and simplifying results in the objective function:

(A.2.1) $O B J_{i}=[A-B X] x_{i}-\lambda_{i} P_{M} x_{i}$.

Maximization of (A.2.1) results in the $i^{\text {th }}$ retailer's reaction function:

(A.2.2) $x_{i}=\frac{A-B \bar{X}_{i}-\lambda_{i} P_{M}}{2 B}$,

where $\bar{X}_{i}=X-x_{i}$. Summing over all retailers yields:

(A.2.3) $\Sigma x_{i}=X=\frac{n A-B(n-1) X-\Sigma \lambda_{i} P_{M}}{2 B}$.

Solving (A.2.3) results in the market output: 
(A.2.4) $X=\frac{n A-\Sigma \lambda_{i} P_{M}}{B(n+1)}$

Use of the definition $\bar{X}_{i}=X-x_{i}$ and substitution of (A.2.4) into (A.2.3) yields the individual retailer's output while the retail price is obtained from the inverse demand curve and (A.2.3). These are, respectively:

(A.2.5) $x_{i}=\frac{A+P_{M}\left(\sum_{j \neq i} \lambda_{j}-n \lambda_{i}\right)}{B(n+1)}$,

(A.2.6) $P_{R}=\frac{A+P_{M} \Sigma \lambda_{i}}{n+1}$.

The retailer price-cost margin $\left(P_{R}-P_{M}\right)$ with equations (A.2.5) and (A.2.6) can be used to derive the ith retailer's realized profits in terms of the parameters $\lambda_{i}$ :

$$
\text { (A.2.7) } \pi_{i}=\frac{\left[A+P_{M}\left(\Sigma \lambda_{i}-(n+1)\right)\right]\left[A+P_{M}\left(\sum_{j \neq i} \lambda_{j}-n \lambda_{i}\right)\right]}{B(n+1)^{2}} .
$$

Differentiating (A.2.7) with respect to $\lambda_{i}$, and noting that because of symmetry of response $\lambda_{i}=\lambda_{j}$, yields the profit maximizing value of $\lambda_{i}$ :

(A.2.8) $\lambda_{i}=\frac{n(n+1)}{n^{2}+1}-\frac{(n-1) A}{\left(n^{2}+1\right) P_{M}}$.

Substituting (A.2.8) into (A.2.5) and (A.2.6) results in the retailer output, market output, and retail price:

(A.2.9) $x_{i}=\frac{n\left(A-P_{M}\right)}{B\left(n^{2}+1\right)}$

(A.2.10) $X=\frac{n^{2}\left(A-P_{M}\right)}{B\left(n^{2}+1\right)}$,

Equation (A.2.10) can be used to derive the manufacturer's profit expressed in terms of its price-cost margin. This yields the optimal manufacturer price $P_{M}=\frac{\left(A+C_{M}\right)}{2}$. Use of this manufacturer price in the various equations results in the equilibrium conditions listed in Table 1.

A. 3. Derivations for pure profit maximizing retailers operating with various manufacturer incentives 
The derivations in this section follow a similar set of steps for each of the 3 sales incentive schemes.

\section{Constant per unit sales incentive, $d$ :}

The retailer's profit function is

$$
\text { (A.3.1) } \pi_{i}=[A-B X] x_{i}-P_{M} x_{i}+d x_{i} \text {. }
$$

Maximization of (A.3.1) results in the $i^{\text {th }}$ retailer's reaction function:

(2) $x_{i}=\frac{A+d-B \bar{X}_{i}-P_{M}}{2 B}$, where $\bar{X}_{i}=X-x_{i}$. Due to symmetry in retailer output, $\bar{X}_{i}=(n-1) x_{i}$.

Solving (A.3.2) results in the $i^{\text {th }}$ retailer's output of

$$
\text { (A.3.3) } x_{i}=\frac{A+d-P_{M}}{B(n+1)} \text {. }
$$

and use of (A.3.3) in the demand function results in the equilibrium retail price of

$$
\text { (A.3.4) } P_{R}=\frac{A-n\left(d-P_{M}\right)}{n+1} \text {. }
$$

The manufacturer's profit is given by:

$$
\text { (A.3.5) } \pi_{M}=\left(P_{M}-C_{M}-d\right) n x_{i} \text {. }
$$

Use of (A.3.3) in equation (A.3.5) and maximization of the manufacturer's profit with respect to $P_{M}$ results in:

$$
\text { (A.3.6) } P_{M}=\frac{\left(A+C_{M}\right)}{2}+d \text {. }
$$

Using (A.3.6) in the various equations results in equilibrium results presented in Table 2.

Per unit sales incentive a function of a retailer's own sales, $d x_{i}$ :

The retailer's profit function is

$$
\text { (A.3.7) } \pi_{i}=[A-B X] x_{i}-P_{M} x_{i}+\left(d x_{i}\right) x_{i} \text {. }
$$

Maximization of (A.3.7) results in the ith retailer's reaction function:

$$
\begin{aligned}
& \text { (A.3.8) } x_{i}=\frac{A-B \bar{X}_{i}-P_{M}}{2(B-d)} \text {, where } \bar{X}_{i}=X-x_{i} \text {. Due to symmetry in retailer } \\
& \text { output, } \bar{X}_{i}=(n-1) x_{i} \text {. }
\end{aligned}
$$


Solving (A.3.8) results in the $i^{\text {th }}$ retailer's output of

$$
\text { (A.3.9) } x_{i}=\frac{A-P_{M}}{B(n+1)-2 d} \text {. }
$$

and use of (A.3.9) in the demand function results in the equilibrium retail price of

$$
\text { (A.3.10) } P_{R}=A-\frac{B n\left(A-P_{M}\right)}{B(n+1)-2 d} \text {. }
$$

The manufacturer's profit is given by:

(A.3.11) $\pi_{M}=\left(P_{M}-C_{M}-d x_{i}\right) n x_{i}$.

Use of (A.3.9) in equation (A.3.11) and maximization of the manufacturer's profit with respect to $P_{M}$ results in:

(A.3.12) $P_{M}=\frac{A B(n+1)+C_{M}(B-2 d+B n)}{2(B-d+B n)}$.

Using (A.3.12) in the various equations results in equilibrium results presented in Table 3.

Per unit sales incentive a function of all retailer sales, $d\left(\sum_{i=1}^{n} x_{i}\right) x_{i}$ :

The retailer's profit function is

(A.3.13) $\pi_{i}=[A-B X] x_{i}-P_{M} x_{i}+\left(d\left(\sum_{i=1}^{n} x_{i}\right)\right) x_{i}$.

Maximization of (A.3.13) results in the $i^{t h}$ retailear's reaction function:

(A.3.14) $x_{i}=\frac{A-B \bar{X}_{i}+d \bar{X}_{i}-P_{M}}{2(B-d)}$, where $\bar{X}_{i}=X-x_{i}$. Due to symmetry in retailer output, $\bar{X}_{i}=(n-1) x_{i}^{2}$.

Solving (A.3.14) results in the $i^{\text {th }}$ retailer's output of

$$
\text { (A.3.15) } x_{i}=\frac{A-P_{M}}{(n+1)(B-d)} \text {. }
$$

and use of (A.3.15) in the demand function results in the equilibrium retail price of

$$
\text { (A.3.16) } P_{R}=A-\frac{B n\left(A-P_{M}\right)}{(n+1)(B-d)} \text {. }
$$


The manufacturer's profit is given by:

(A.3.17) $\pi_{M}=\left(P_{M}-C_{M}-d\left(\sum_{i=1}^{n} x_{i}\right)\right) n x_{i}$.

Use of (A.3.15) in equation (A.3.17) and maximization of the manufacturer's profit with respect to $P_{M}$ results in:

(A.3.18) $P_{M}=\frac{C_{M}(B-d)(n+1)+A(d(n-1)+B(n+1))}{2(B-d+B n)}$

Using (A.3.18) in the various equations results in equilibrium results presented in Table 4.

A. 4. Derivations for mixed objective function retailers operating with various manufacturer incentives

The derivations in this section follow a similar set of steps for each of the 3 sales incentive schemes.

\section{Constant per unit sales incentive, $d$ :}

The objective function for the managaer is $O B J_{i}=\lambda_{i} \pi_{i}+\left(1-\lambda_{i}\right) P_{R} x_{i}+d x_{i}$. Using the demand function and simplifying results in the objective function:

(A.4.1) $O B J_{i}=\left[A-B X-\lambda_{i} P_{M}\right] x_{i}+d x_{i}$

Maximization of (A.4.1) results in the $i^{\text {th }}$ retailer's reaction function:

(A.4.2) $x_{i}=\frac{A-B \bar{X}_{i}-\lambda_{i} P_{M}+d}{2 B}$,

where $\bar{X}_{i}=X-x_{i}$. Summing over all retailers yields:

(A.4.3) $\Sigma x_{i}=X=\frac{n A-B(n-1) X-\Sigma \lambda_{i} P_{M}+n d}{2 B}$.

Solving (A.4.3) results in the market output:

(A.4.4) $X=\frac{n A-\Sigma \lambda_{i} P_{M}+n d}{B(n+1)}$.

Substitution of (A.4.4) into (A.4.2) and use of the definition $\bar{X}_{i}=X-x_{i}$ yields the retailer's output while the retail price is obtained from the inverse demand 
curve and (A.4.3). These are, respectively:

$$
\text { (A.4.5) } x_{i}=\frac{A+d+P_{M}\left(\sum_{j \neq i} \lambda_{j}-n \lambda_{i}\right)}{B(n+1)},
$$

$$
\text { (A.4.6) } P_{R}=\frac{A+P_{M} \Sigma \lambda_{i}-n d}{n+1} \text {. }
$$

The retailer price-cost margin $\left(P_{R}-P_{M}+d\right)$ with equations (A.4.5) and (A.4.6) can be used to derive the $i^{\text {th }}$ retailer's realized profits in terms of the parameters $\lambda_{i}$ :

$$
\text { (A.4.7) } \pi_{i}=\frac{\left[A+d+P_{M}\left(\sum \lambda_{i}-(n+1)\right)\right]\left[A+d+P_{M}\left(\sum_{j \neq i} \lambda_{j}-n \lambda_{i}\right)\right]}{B(n+1)^{2}} .
$$

Differentiating (A.4.7) with respect to $\lambda_{i}$, and noting that because of symmetry of response $\lambda_{i}=\lambda_{j}$, yields the profit maximizing value of $\lambda_{i}$ :

$$
\text { (A.4.8) } \lambda_{i}=\frac{n(n+1)}{n^{2}+1}-\frac{(n-1)(A+d)}{\left(n^{2}+1\right) P_{M}} \text {. }
$$

Substituting (A.4.8) into (A.4.5) results in the retailer output and market output:

$$
\begin{aligned}
& \text { (A.4.9) } x_{i}=\frac{n\left(A+d-P_{M}\right)}{B\left(n^{2}+1\right)}, \\
& \text { (A.4.10) } X=\frac{n^{2}\left(A+d-P_{M}\right)}{B\left(n^{2}+1\right)},
\end{aligned}
$$

Equation (A.4.10) can be used to derive the manufacturer's profit expressed in terms of its price-cost margin. This yields the optimal manufacturer price $P_{M}=\frac{\left(A+C_{M}\right)}{2}+d$. Use of this manufacturer price in the various equations results in the equilibrium conditions listed in Table 2.

\section{Per unit sales incentive a function of a retailer's own sales, $d x_{i}$ :}

The objective function for the manager is $O B J_{i}=\lambda_{i} \pi_{i}+\left(1-\lambda_{i}\right) P_{R} x_{i}+d\left(x_{i}\right) x_{i}$. Using the demand function and simplifying results in the objective function: 
(A.4.11) $O B J_{i}=\left[A-B X-\lambda_{i} P_{M}\right] x_{i} \cdot+\left(d x_{i}\right) x_{i}$

Maximization of (A.4.11) results in the $i^{\text {th }}$ retailer's reaction function:

(A.4.12) $x_{i}=\frac{A-B \bar{X}_{i}-\lambda_{i} P_{M}}{2(B-d)}$,

where $\bar{X}_{i}=X-x_{i}$. Summing over all retailers yields:

(A.4.13) $\Sigma x_{i}=X=\frac{n A-B(n-1) X-\Sigma \lambda_{i} P_{M}}{2(B-d)}$.

Solving (A.4.13) results in the market output:

(A.4.14) $X=\frac{n A-\Sigma \lambda_{i} P_{M}}{B(n+1)-2 d}$.

Use of the definition $\bar{X}_{i}=X-x_{i}$ and substitution of (A.4.14) into (A.4.13) yields the individual retailer's output while the retail price is obtained from the inverse demand curve and (A.4.13). These are, respectively:

$$
\begin{aligned}
& \text { (A.4.15) } x_{i}=\frac{A-P_{M} \lambda_{i}-\frac{B\left(n A-P_{M} \sum_{i=1}^{n} \lambda_{i}\right)}{B(n+1)-2 d}}{(B-2 d)}, \\
& \text { (A.4.16) } P_{R}=A-\frac{B n P_{M}\left(2 d \lambda_{i}-B\left(\lambda_{i}(n+1)-\sum_{i=1}^{n} \lambda_{i}\right)\right.}{(B-2 d)^{2}} .
\end{aligned}
$$

The retailer price-cost margin $\left(P_{R}-P_{M}+d x_{i}\right)$ with equations (A.4.15) and (A.4.16) can be used to derive the $i^{\text {th }}$ retailer's realized profits in terms of the parameters $\lambda_{i}$ :

$$
\begin{aligned}
& \text { (A.4.17) } \pi_{i}=\frac{1}{(B-2 d)^{2}(B-2 d+B n)^{2}}\left(\left(A(B-2 d)+P_{M}\left(2 d \lambda_{i}-B\left(\lambda_{i}+n \lambda_{i}-\sum_{i=1}^{n} \lambda_{i}\right)\right)\right)\right. \\
& \left.\left(A\left(B^{2}-3 B d+2 d^{2}\right)-P_{M}\left(B^{2}\left(n+1-\sum_{i=1}^{n} \lambda_{i}\right)-2 d^{2}\left(\lambda_{i}-2\right)+B d\left(n\left(\lambda_{i}-2\right)-4+\lambda_{i}+\sum_{i=1}^{n} \lambda_{i}\right)\right)\right)\right)
\end{aligned}
$$

Differentiating (A.4.17) with respect to $\lambda_{i}$, and noting that because of symmetry of response $\lambda_{i}=\lambda_{j}$, yields the profit maximizing value of $\lambda_{i}$ :

(A.4.18) $\lambda_{i}=\frac{P_{M}\left(4 d^{2}+B^{2} n(n+1)-2 B(d(2 n+1))\right)-A B^{2}(n-1)}{P_{M}\left(4 d^{2}-2 B d(2 n+1)+B^{2}\left(n^{2}+1\right)\right.}$. 
Substituting (A.4.18) into (A.4.15) results in the retailer output and market output:

(A.4.19) $x_{i}=\frac{\left(A-P_{M}\right)(B n-2 d)}{4 d^{2}-2 B d(2 n+1)+B^{2}\left(n^{2}+1\right)}$,

(A.4.20) $X=\frac{n\left(A-P_{M}\right)(B n-2 d)}{4 d^{2}-2 B d(2 n+1)+B^{2}\left(n^{2}+1\right)}$,

Equation (A.4.20) can be used in the manufacturer's profit equation to derive the manufacturer's profit expressed in terms of its price-cost margin. This yields the optimal manufacturer price $P_{M}=\frac{A B\left(-2 d(n+1)+B\left(n^{2}+1\right)\right)+C_{M}\left(4 d^{2}-2 B(d+2 d n)+B^{2}\left(n^{2}+1\right)\right)}{2\left(2 d^{2}-B d(2+3 n)+B^{2}\left(n^{2}+1\right)\right.}$. Use of this manufacturer price in the various equations results in the equilibrium conditions listed in Table 3.

Per unit sales incentive a function of all retailer sales, $d\left(\sum_{i=1}^{n} x_{i}\right) x_{i}$ :

The objective function for the manager is $O B J_{i}=\lambda_{i} \pi_{i}+\left(1-\lambda_{i}\right) P_{R} x_{i}+d\left(\sum_{i=1}^{n} x_{i}\right) x_{i}$. Using the demand function and simplifying results in the objective function:

(A.4.21) $O B J_{i}=\left[A-B X-\lambda_{i} P_{M}\right] x_{i}+d X x_{i}$

Maximization of (A.4.21) results in the $i^{\text {th }}$ retailer's reaction function:

(A.4.22) $x_{i}=\frac{A-(B-d) \bar{X}_{i}-\lambda_{i} P_{M}}{2(B-d)}$,

where $\bar{X}_{i}=X-x_{i}$. Summing over all retailers yields:

(A.4.23) $\Sigma x_{i}=X=\frac{n A-(B-d)(n-1) X-\Sigma \lambda_{i} P_{M}}{2(B-d)}$.

Solving (A.4.23) results in the market output:

(A.4.24) $X=\frac{n A-\Sigma \lambda_{i} P_{M}}{(B-d)(n+1)}$.

Use of the definition $\bar{X}_{i}=X-x_{i}$ and substitution of (A.4.24) into (A.4.23) yields the individual retailer's output while the retail price is obtained from the inverse demand curve and (A.4.23). These are, respectively: 
(A.4.25) $x_{i}=\frac{A+P_{M}\left(\sum_{j \neq i} \lambda_{j}-n \lambda_{i}\right)}{(B-d)(n+1)}$

(A.4.26) $P_{R}=A-\frac{B n A+P_{M} \Sigma \lambda_{i}}{(B-d)(n+1)}$

The retailer price-cost margin $\left(P_{R}-P_{M}+d X\right)$ with equations (A.4.25) and (A.4.26) can be used to derive the $i^{\text {th }}$ retailer's realized profits in terms of the parameters $\lambda_{i}$ :

(A.4.27) $\pi_{i}=\frac{\left[A+P_{M}\left(\sum \lambda_{i}-(n+1)\right)\right]\left[A+P_{M}\left(\sum_{j \neq i} \lambda_{j}-n \lambda_{i}\right)\right]}{(B-d)(n+1)^{2}}$.

Differentiating (A.4.27) with respect to $\lambda_{i}$, and noting that because of symmetry of response $\lambda_{i}=\lambda_{j}$, yields the profit maximizing value of $\lambda_{i}$ :

(A.4.28) $\lambda_{i}=\frac{n(n+1)}{n^{2}+1}-\frac{(n-1) A}{\left(n^{2}+1\right) P_{M}}$ a

Substituting (A.4.28) into (A.4.25) results in the retailer output and market output:

(A.4.29) $x_{i}=\frac{n\left(A-P_{M}\right)}{(B-d)\left(n^{2}+1\right)}$,

(A.4.30) $X=\frac{n^{2}\left(A-P_{M}\right)}{(B-d)\left(n^{2}+1\right)}$

Equation (A.4.30) can be used in the manufacturer's profit equation to derive the manufacturer's profit expressed in terms of its price-cost margin. This yields the optimal manufacturer price $P_{M}=\frac{C_{M}(B-d)\left(n^{2}+1\right)+A\left(d\left(n^{2}-1\right)+B\left(n^{2}+1\right)\right)}{2\left(B-d+B n^{2}\right)}$. Use of this manufacturer price in the various equations results in the equilibrium conditions listed in Table 4.

\section{REFERENCES}

Adachi, T. and Ebina, T. (2014). Cost Pass-Through and Inverse Demand Curvature in Vertical Relationships with Upstream and Downstream Competition. Economics Letters, 124(3), 465-68 
Baumol. W. J. (1958).On the Theory of Oligopoly. Economica, 25(99), 187-198.

Bresnahan, T. F. and Reiss, P. C. (1985). Dealer and Manufacturer Margins. RAND Journal of Economics, 16(2), 253-68.

Cowan, S. (2012). Third-Degree Price Discrimination and Consumer Surplus. Journal of Industrial Economics, 60(2), 333-45.

Fershtman, C. and Judd, K. (1987). Equilibrium Incentives in Oligopoly. American Economic Review, 77(5), 927-40.

Hamilton, J. H. (1990). Resale Price Maintenance in a Model of Consumer Search. Managerial and Decision Economics, 11(2), 87-98.

Hegji, C. E. and Moore, E. C. (2006).On the Economics of Manufacturers and Dealers: A Reexamination. Southwestern Economic Review, 33(1), 107-20.

Spengler, J. (1950) Vertical Integration and Antitrust Policy. Journal of Political Economy, 58(4), 347-352.

Weyl, E.G. and Fabinger, M. (2013). Pass-Through as an Economic Tool: Principles of Incidence under Imperfect Competition. Journal of Political Economy, 121(3), 528-83.

\section{BRIEF BIOGRAPHICAL SKETCH OF AUTHORS}

Dr. Evan Moore joined the Department of Economics at Auburn University Montgomery in 2002. He is a professor and his primary teaching interests are industrial organization, game theory, and microeconomic theory. His current areas of research include industrial organization and sports financial markets. He has published in a variety of journals including the American Economic Review.

Dr. James Francisco joined the Auburn University Montgomery faculty in 2013. He is an assistant professor whose research and teaching interests include law and economics, industrial organization and competition economics, and sports economics. 